\title{
Antiretroviral Therapy: Level of Adherence and Its Determinants Among Patients on Treatment in Different Health Facilities. A Cross Sectional Study in Oromia Regional State, Ethiopia
}

Tolossa E Chaka $^{1 *}$, Sileshi G Abeya ${ }^{1}$, Abebe M Adlo ${ }^{1}$, Tilaye W Abebe ${ }^{1}$, Shalo D Hamuse ${ }^{2}$, Mihretu T Lencha ${ }^{2}$ and Zelalem H Jemal ${ }^{2}$

${ }^{1}$ Adama Hospital Medical College, Adama, Ethiopia

${ }^{2}$ Oromia Regional Health Bureau, Addis Ababa, Ethiopia

\begin{abstract}
Background: HIVIAIDS pandemic is the world's most deadly disease that has killed more than 25 million people so far. Appropriate antiretroviral viral treatment (ART) reduces mortality and morbidity and enhances quality of life. Adherence to both follow up clinics and drugs is crucial to this effect.
\end{abstract}

Objective: To assess level of adherence to antiretroviral treatment and its determinants among patients on ART in Oromia regional state, Ethiopia.

Methods: Cross-sectional study design was used. For the study purpose, the region was divided into four strata so that different socioeconomic characteristics of the study population will be represented. List of health facilities that had a case load of $>500$ patients across the strata was used as sampling frame and health facilities were randomly selected. The Sample size was proportionally assigned to health facilities and every other patient visiting the selected health facility was included and a total of 1632 study participants (age 15 years and above) were interviewed. The patients' follow up chart was used to extract baseline clinical data. Epi Info 7 was used for data entry and analyzed using SPSS 20. Descriptive statistics were used to determine sociodemographic characteristics and level of adherence. Logistic regression model was used to identify predictors of adherence.

Results: Ninety seven percent of patients had good adherence to ART. Factors associated with better adherence were housewives (AOR, 5.10; 95\% Cl, 1.30, 19.98), baseline CD4 count <350 cells/ml (AOR: $2.21 ; 95 \% \mathrm{Cl}: 1.13,4.34$ ) and patients free of addictive substances (AOR: $7.42 ; 95 \% \mathrm{Cl}: 1.46,37.81)$. Significant proportions of patients believe that worshiping and holy water ("Tsebel") can cure HIVIAIDS.

Conclusion: The vast majority $(97 \%)$ of the respondents were in optimum adherence to the treatment. Various factors were associated with optimum adherence to antiretroviral treatment. Knowledge and attitude of PLWHA towards ART should be addressed carefully.

Keywords: Antiretroviral treatment; Adherence; Associated factors; Oromia; Ethiopia

\section{Abbreviations}

ART: Antiretroviral Therapy; ARV: Antiretroviral; $\mathrm{CD}_{4}$ : Cluster of Differentiation; HIV/AIDS: Human Immunodeficiency Virus/ Acquired Immunodeficiency Syndrome; IDI: In-Depth Interview; IPT: Isoniazid Prophylactic Treatment; LTFU: Lost to Follow-Up; OIs: Opportunistic Infections; PLWHA: People Living with HIV/AIDS; PLWHIV: People Living with HIV; PMTCT: Prevention of Mother to Child Transmission; WHO: World Health Organization

\section{Introduction}

Sub-Saharan countries contribute most $(63 \%$ of the 24.7 million PLWHA) of the HIV/AIDS patients to the world [1]. The initial challenge in combating HIV/AIDS epidemic was an access to antiretroviral (ARV) medicines [1,2]. However, increasing production and decrease in the cost of the ARVs dramatically facilitated the scaling up of antiretroviral therapy (ART) programs worldwide [1]. In the late 1990s,combinations of ART medications were introduced even though patient adherence had emerged as a program challenge [3].

The ARV drugs suppress viral replication, restore the immune status, halt progression of disease, increase survival rates, reduce morbidity and improve quality of life $[1,2]$. Thus, the use of ART revitalized communities and transformed perceptions on HIV/AIDS from a plague to a manageable chronic illness [4]. Even though there are many benefits of ART, very high level of adherence (at least 95\%) is needed to ensure the optimal benefits [2,5]. Poor adherence along with other factors can lead to virological, immunological and clinical failures with ultimate emergence of drug resistant strains $[1,2,4,6,7]$. When an individual develops resistance to the first-line ARVs, they have to be treated with second line ARVs which are more expensive [8].

\section{Theoretical framework of ART adherence predictors}

Studies showed that different factors affect ART adherence and lost to follow up. These factors can be related and not limited to: sociodemographic, treatment regimen related, disease characteristics, patient-provider relationship, clinical setting, individual patient related and the quality of healthcare services $[9,10]$.

*Corresponding author: Tolossa E Chaka, Consultant Pediatrician, Department of Pediatrics and Child Health Adama Hospital Medical College, P.O. Box: 84 Adama, Ethiopia, Tel: +251911413135; E-mail: tecb2006@gmail.com

Received October 06, 2016; Accepted October 18, 2016; Published October 25 2016

Citation: Chaka TE, Abeya SG, Adlo AM, Abebe TW, Hamuse SD, et al. (2016) Antiretroviral Therapy: Level of Adherence and Its Determinants Among Patients on Treatment in Different Health Facilities. A Cross Sectional Study in Oromia Regional State, Ethiopia. J AIDS Clin Res 7: 629. doi: 10.4172/2155-6113.1000629

Copyright: $\odot 2016$ Chaka TE, et al. This is an open-access article distributed under the terms of the Creative Commons Attribution License, which permits unrestricted use, distribution, and reproduction in any medium, provided the original author and source are credited. 
Citation: Chaka TE, Abeya SG, Adlo AM, Abebe TW, Hamuse SD, et al. (2016) Antiretroviral Therapy: Level of Adherence and Its Determinants Among Patients on Treatment in Different Health Facilities. A Cross Sectional Study in Oromia Regional State, Ethiopia. J AIDS Clin Res 7: 629. doi: 10.4172/2155-6113.1000629

Page 2 of 7

Socio-demographic factors: Lack of transport and transportation costs, food shortage, stigma and discrimination and lack of social/ family support are some of the socio-demographic predictors of ART adherence. In a study conducted in Yirgalem Hospital, respondents who lived more than $47 \mathrm{~km}$ away from ART site (AOR, 2.48; $95 \%$ CI: 1.24 to 4.98 ) were more likely to be lost from treatment [10]. In another qualitative study, financial constraints, lack of transport and inability to pay costs for tests and OI drugs were a great distress to the vast majority of patients [11]. In the study done in Ethiopia, most ART patients are poor and many discontinue treatment because they do not have adequate food with which to take medication [12]. The study done by Ayala et al. showed that patients who got family support were two times more likely to adhere than others [13].

Treatment and disease related factors: Antiretroviral treatment consists of a complex regimen that can include multiple pills a day, with multiple dosing throughout the day and specific food and fluid related instructions. These are often difficult to follow for patients and contribute to poor adherence. The higher the pill burden, the lower is the adherence [14]. Patients with higher CD4 counts tend to be less adherent. In a systemic review and meta analysis by Bock Peter et.al, the odds of being adherent was marginally lower for patients in the higher CD4 count group (pooled OR 0.9; 95\% CI 0.84-0.96) [15]. On the other hand, antiretroviral medications often have many side effects, some of which are temporary: diarrhea, fatigue, nausea and vomiting; while others may be permanent or long lasting: peripheral neuropathy, physical changes in body appearance, lipoatrophy/lipodystrophy, metabolic changes. Studies have shown that when patients experience side-effects, they tend to stop treatment or take it irregularly [14].

\section{Health care system and health care team factors}

Access to care and the patient health care provider relationship were found to be important factors that determined satisfactory adherence to ART [16]. Meaningful and supportive relationship between the patient and health care provider can help to overcome significant barriers to adherence [1]. Patients become frustrated with health care providers when misunderstandings occur, treatment becomes complex, sideeffects go unmanaged and the patient is blamed for being a "bad patient”. One study showed that, difficulty in following physician's instructions was a significant barrier to medications adherence [17]. Satisfaction in the health care service is an important indicator of the quality of the patient-provider relationship. As Bosworth et al. pointed out, patients who are not satisfied with their health care provider are more likely to reject medical advice [18]. Another study also revealed that dissatisfaction with the health services is a predictor of nonadherence [19].

\section{Individual patient related factors}

In a qualitative study done in Ethiopia, the majority of patients had disclosed their status to their close family and friends, but very few had disclosed it to the community [20]. The fear and experience of stigma and discrimination often prevents PLHIV from disclosing their HIV status. Low rates of HIV disclosure and high levels of perceived HIV associated stigma can pose a barrier to adherence [21]. Some PLHIV do not have a good understanding of HIV and the common beliefs about the causes of HIV and basic etiology of HIV can reduce motivation for treatment. In addition, misconceptions and rumors related to ARVs can affect adherence [22]. In Ethiopia, religious PLHA often take holy water as treatment for HIV instead of ARVs [12]. Drinking alcohol (AOR, $0.21 ; 95 \% \mathrm{CI}, 0.07$ to 0.62 ) was also associated with nonadherence to doses of ARVs [23].
Different facility based studies across the country showed that the level of ART adherence varies between $87-94 \%$ [4,10,24-26]. There is no national or regional study done to determine prevalence of ART adherence and its predictors. The aim of this study is to assess the prevalence of ART adherences and associated factors at regional level.

\section{Methods}

\section{Study area}

Oromia regional state is the largest and populous region located at the central part of the country, Ethiopia [27,28]. Being the largest region that covers the central land mass of the country, it includes high HIV prevalence corridors. According to the national HIV/AIDS projections for Ethiopia, the prevalence of HIV infection in 2014 was $1.2 \%$ ( $1.6 \%$ and $0.8 \%$ for women and men, respectively) among the adult population. The Oromia region HIV/AIDS situation is similar with that of national data. There are 42 Hospitals and over 1,300 Health Centers in the region [28]. Of these health facilities, 318 (All Hospitals and 276 Health Centers) are providing ART service for over 80,000 clients.

\section{Study design}

Facility based cross sectional study was conducted to assess the level of antiretroviral treatment adherence and associated factors. Stratified sampling method was used. First, Oromia region was stratified into four strata based on geographical and socio-cultural relative similarity.

Second, based on the latest regional health bureau report [28], we identified all health facilities with at least 500 patients on ART. We used this case load as inclusion criteria for the health facilities in the study to be able to get the required sample from the facility. The latest regional health bureau ART data were also used to identify the proportion of patients currently on ART to be included in the study per stratum. The health facilities to be included in the study were randomly selected from the list of health facilities with patient load of 500 and above in the four strata.

The third step was determining the number of patients to be interviewed per health facility. This was done by proportionally dividing the sample size allocated to the respective stratum to the health facilities based on the caseload each health facility had. Finally, all patients visiting the selected health facility during the study period were consecutively interviewed until the allocated sample is obtained. Fear of information contamination is avoided by interviewing every other patient where the caseload is high. Baseline and treatment information was extracted from electronic medical records for all interviewed patients. Single population proportion formula was used to calculate sample size with design effect to increase the power of the study. Sampling procedure is indicated by Figure 1 .

\section{Data collection}

After written consent was obtained, a semi-structured questionnaire was used to interview all study participants. Data extraction format was used to extract baseline clinical data from the medical records. Data collectors and supervisors were trained for three days prior to the data collection. The data from questionnaires and medical records were linked by using the unique ART number.

\section{Data management and analysis}

Epi Info version 7.1.4 was used for data entry. The data were exported to SPSS version 20 for cleaning and analysis. Univariate, 


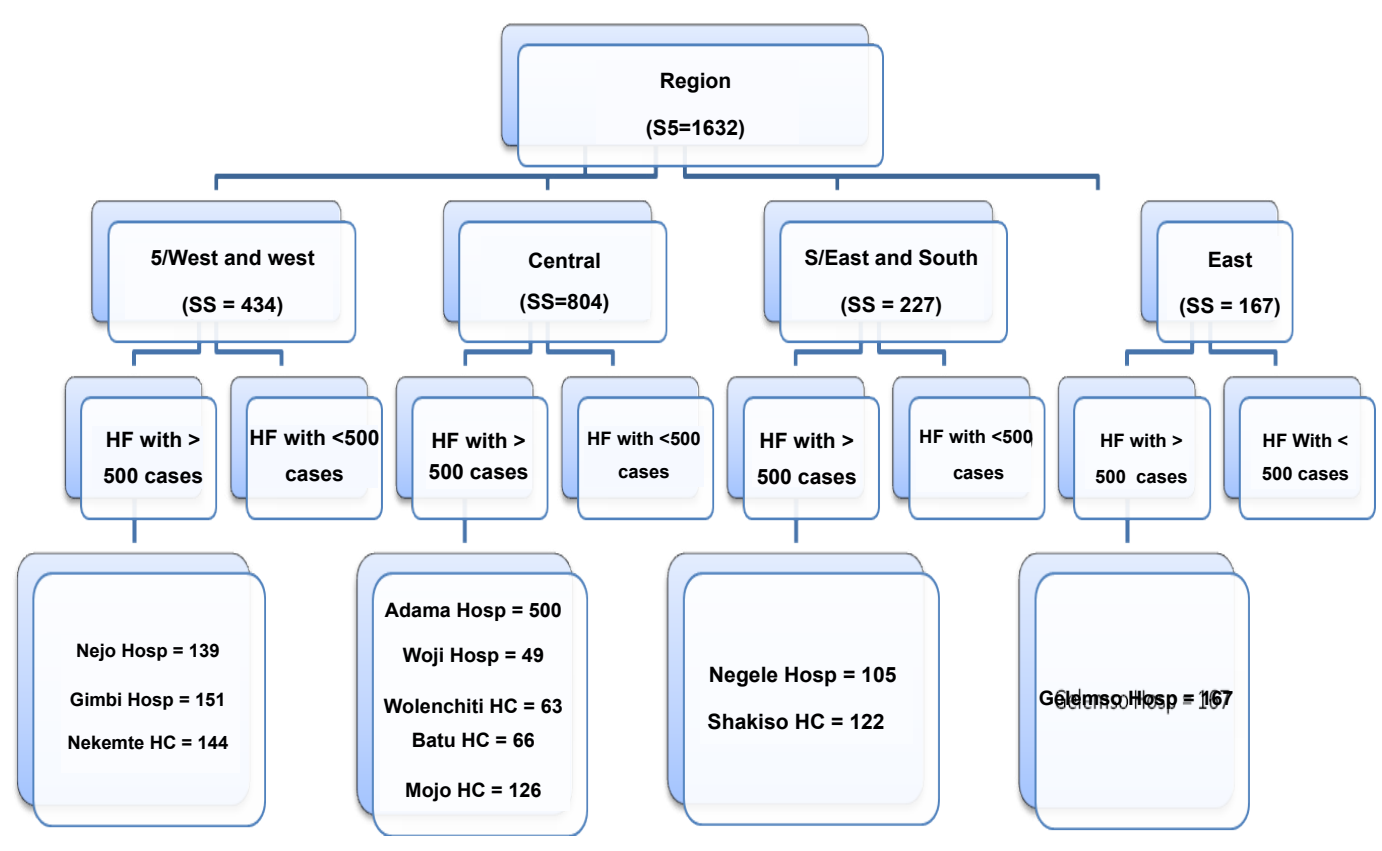

Figure 1: Schematic presentation of sampling procedure.

bivariate and multivariate analyses were performed. Stratified analysis by predictors of ART adherence was conducted. Proportions, tables and graphs were used to describe the study population. Appropriate statistical analysis models were used after checking for assumptions. Binary logistic regression was used to identify the independent predictors of adherence. Multicolinearity was checked to rule out interactions among the independent variables and any independent variable with greater than $60 \%$ of Colinearity was dropped from the analysis. Colinearity between categorical variables was assessed by looking at the values of variance inflation factor (VIF) and those larger than 10 were excluded from the fitted model $[29,30]$. A Confidence level of $95 \%$ was used to determine statistical significance and p-value of less than or equal to 0.05 was considered as statistically significant association.

\section{Ethical Consideration}

The ethical approval was secured from Adama Hospital Medical College ethical review committee. An accompanying letter of permission was also obtained from the Regional Health Bureau for all included health facilities. Written informed consent was obtained and participants/care givers were informed that they have the right to decline from the study. The study participants' Confidentiality of the information was assured and privacy of the respondents' was maintained.

\section{Result}

\section{Description of the study subjects}

A total of 1631 adult patients living with HIV/AIDS and on ART were included in the study. Two third (66.1\%) of the respondents were females. Sixty eight percent of the participants were between 25-44 years of age with the median age of 36 years (IQR=14 years). The majorities $(82.3 \%)$ were urban residents and more than half $(52.0 \%)$ were married. However, about one in six $(14.0 \%)$ of the study participants were never married at the time of the interview.
The predominant ethnic group (64.1\%) in the study area was Oromo followed by Amhara (27.7\%). About two third of the respondents were Orthodox Christian by religion followed by Muslims (12.6\%). One quarter (25\%) of the respondents were unable to read and write, while about one in five were educated to the level of elementary $\left(1-8^{\text {th }}\right.$ grade $)$ school. Day laborers comprise $27 \%$, followed by governmental or NGO employees (15.3\%) (Table1).

The median estimated monthly income was calculated to be 700 ETB $(\mathrm{IQR}=900 \mathrm{ETB})$, and nearly half of participants were earning below 600 ETB (Figure 2). Most of the respondents (68.6\%) live with their families, while one out of five are living alone. More than one in ten (13.2\%) of the respondents never disclosed their HIV statuses to their relatives or friends. About 611 respondents (38\%) reported no social support during the study period. Nearly eleven percent of the respondents reported using addictive substances like Khat, Cigarette and alcohol (Table 2).

\section{Clinical background and ART adherences of the study participants}

At baseline, the vast majority (95\%) of the respondent's functional status was working. Two third $(66.8 \%)$ of the respondents started ART because their baseline CD 4 count was $<350$ cells $/ \mathrm{ml}$. When asked about the number of pills taken per day during the last one month prior to the study, two out of five (39.9\%) of the respondents reported that they took two pills and $5 \%$ of the study participants took four and more pills per day. Out of all respondents, $171(10.5 \%)$ missed at least one dose in the last one month prior to the survey and 246 (16.3\%) reported to have the side effects of the regimen (Table 3 ).

\section{Level of ART adherence}

The result of this study showed that ART adherence status of 1608 (98.8\%) participants from the Logbook was good. Similarly, ART adherence status according to the data from the interviews, 1586 (97\%) of the respondents had a good adherence status for one month prior to the study period. 
Citation: Chaka TE, Abeya SG, Adlo AM, Abebe TW, Hamuse SD, et al. (2016) Antiretroviral Therapy: Level of Adherence and Its Determinants Among Patients on Treatment in Different Health Facilities. A Cross Sectional Study in Oromia Regional State, Ethiopia. J AIDS Clin Res 7: 629. doi: 10.4172/2155-6113.1000629

Page 4 of 7

\begin{tabular}{|c|c|c|}
\hline Variables & Frequency & Percent \\
\hline \multicolumn{3}{|l|}{ Sex $(n=1631)$} \\
\hline Male & 553 & 33.9 \\
\hline Female & 1078 & 66.1 \\
\hline \multicolumn{3}{|l|}{ Age Category $(n=1608)$} \\
\hline $15-24$ years & 107 & 6.7 \\
\hline $25-34$ years & 560 & 34.8 \\
\hline $35-44$ years & 549 & 34.1 \\
\hline $45-54$ years & 277 & 17.2 \\
\hline$>=55$ years & 115 & 7.2 \\
\hline \multicolumn{3}{|l|}{ Residence $(n=1631)$} \\
\hline Urban & 1342 & 82.3 \\
\hline Rural & 289 & 17.7 \\
\hline \multicolumn{3}{|l|}{ Marital Status $(n=1629)$} \\
\hline Single & 228 & 14.0 \\
\hline Married or Cohabited & 847 & 52.0 \\
\hline Divorced & 179 & 11.0 \\
\hline Widowed & 238 & 14.6 \\
\hline Others * & 137 & 8.4 \\
\hline \multicolumn{3}{|l|}{ Ethnicity $(n=1629)$} \\
\hline Oromo & 1044 & 64.1 \\
\hline Amhara & 451 & 27.7 \\
\hline Others ** & 134 & 8.2 \\
\hline \multicolumn{3}{|l|}{ Religion ( $n=1629$ ) } \\
\hline Muslim & 206 & 12.6 \\
\hline Orthodox & 1051 & 64.5 \\
\hline Others *** & 372 & 22.8 \\
\hline \multicolumn{3}{|l|}{ Educational status ( $n=1631$ ) } \\
\hline Unable to read and write & 408 & 25.0 \\
\hline Read and write & 82 & 5.0 \\
\hline Elementary $\left(1-8^{\text {th }}\right.$ grade $)$ & 677 & 41.5 \\
\hline High school & 326 & 20.0 \\
\hline Above high school & 138 & 8.5 \\
\hline \multicolumn{3}{|l|}{ Occupation $(n=1631)$} \\
\hline Day Laborer & 439 & 26.9 \\
\hline Farmer & 146 & 9.0 \\
\hline Housewife & 262 & 16.1 \\
\hline Business owner & 346 & 21.2 \\
\hline Employee (GO, NGO, etc.) & 250 & 15.3 \\
\hline Others $* \star \star *$ & 188 & 11.5 \\
\hline
\end{tabular}

NB: * Separated, on and off, ${ }^{* *}$ Tigre, Gurage, Wolayita, ${ }^{* * *}$ Protestant, Catholic, Wakefata, ${ }^{* * * *}$ no occupation, students

Table 1: Socio-demographic characteristics of the study participants, Oromia Regional State, Ethiopia, 2015

\section{Knowledge and attitude of respondents towards ART}

Respondents were asked about HIV/AIDS and ART related knowledge questions and those who scored above and including average were considered as having good knowledge. 1180 (72.3\%) respondents had good knowledge. The study subjects were also asked attitude related questions and those who scored above and including average were considered as having favorable attitude. The score for the attitude was calculated and 1381 (84.7\%) respondents have a favorable attitude (Figure 3).

More than one quarter $(27.5 \%)$ of the respondents believed that HIV/AIDS is curable using ARV drugs. Similarly, about $26.6 \%$ and $9.6 \%$ of the respondents believed that HIV/AIDS is curable by worshiping and holy water respectively (Figure 4 ).

\section{Factors associated with adherence to ART}

Binary logistic regression analysis was used to identify the independent predictors of ART adherence. The outcome ART adherence variable is dichotomized (defined as $1=$ good adherence to ART: $0=$ fair to poor adherence to ART). Each independent variable was tested with the adherence status for the association. Some of the variables were significantly associated with good adherence (Table 4). Among socio-demographic variables residence, occupation and marital status were significantly associated with good adherence to ART $(\mathrm{P}<0.05)$. Use of addictive substances (consuming alcoholic beverages, chewing Khat and cigarette smoking), disclosure of HIV statuses to others and baseline $\mathrm{CD}_{4}$ count were significantly associated behavioral and clinical characteristics $(\mathrm{P}<0.05)$. Rural residents were more likely to have good adherence than urban counterparts (COR:

$($ Median = 700 birr $($ IQR =900) $)$

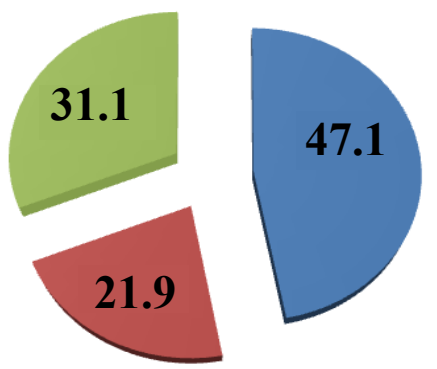

\section{$<=600 \mathrm{ETB}$ \\ 601-1000 ETB \\ 1001 and above ETB}

Figure 2: Percent of estimated average monthly income of the respondents, Oromia Regional State, Ethiopia, 2015.

\begin{tabular}{|c|c|c|}
\hline Variables & Frequency & Percent \\
\hline \multicolumn{3}{|c|}{ Living arrangement $(\mathrm{n}=1631)$} \\
\hline Live Alone & 311 & 19.1 \\
\hline Live with Family & 1119 & 68.6 \\
\hline Live with parents or others & 201 & 12.3 \\
\hline \multicolumn{3}{|l|}{ HIV disclosure status (1607) } \\
\hline Status not disclosed & 212 & 13.2 \\
\hline Status Disclosed & 1395 & 86.8 \\
\hline \multicolumn{3}{|l|}{ Partner HIV status ( $n=919)$} \\
\hline Negative test for HIV & 176 & 19.2 \\
\hline Positive but not on ART & 93 & 10.1 \\
\hline Positive and on ART & 416 & 45.3 \\
\hline HIV status unknown & 106 & 11.5 \\
\hline Partner not alive & 128 & 13.9 \\
\hline \multicolumn{3}{|c|}{ Disclosure status about ART $(n=1620)$} \\
\hline NO ART status disclosure to others than HW & 213 & 13.1 \\
\hline Disclosed ART status to others & 1407 & 86.9 \\
\hline \multicolumn{3}{|l|}{ Social Support (1606) } \\
\hline Has no social & 611 & 38.0 \\
\hline Has social Support & 995 & 62.0 \\
\hline \multicolumn{3}{|c|}{ Use addictive substances (1528) } \\
\hline Doesn't use addictive e drugs & 1361 & 89.1 \\
\hline Uses addictive drugs & 167 & 10.9 \\
\hline \multicolumn{3}{|l|}{ Types of addictive substances } \\
\hline Chew Khat & 73 & 96.1 \\
\hline Smoke cigarette & 25 & 92.6 \\
\hline Drink alcohol & 56 & 96.6 \\
\hline
\end{tabular}

Table 2: Economic and psycho-social characteristics of the study participants, Oromia Regional State, Ethiopia, 2015. 
Citation: Chaka TE, Abeya SG, Adlo AM, Abebe TW, Hamuse SD, et al. (2016) Antiretroviral Therapy: Level of Adherence and Its Determinants Among Patients on Treatment in Different Health Facilities. A Cross Sectional Study in Oromia Regional State, Ethiopia. J AIDS Clin Res 7: 629. doi: 10.4172/2155-6113.1000629

Page 5 of 7

\begin{tabular}{|c|c|c|}
\hline Variables & Frequency & Percent \\
\hline \multicolumn{3}{|c|}{ Baseline functional status $(n=1620)$} \\
\hline Ambulatory & 71 & 4.5 \\
\hline Bedridden & 8 & 0.5 \\
\hline Working & 1550 & 95.0 \\
\hline \multicolumn{3}{|c|}{ WHO clinical stage $(n=1605)$} \\
\hline WHO stage I & 175 & 10.9 \\
\hline WHO stage II & 542 & 33.8 \\
\hline WHO stage III & 562 & 35.0 \\
\hline WHO stage IV & 326 & 20.3 \\
\hline \multicolumn{3}{|l|}{ Baseline $C_{4}(n=1480)$} \\
\hline$<350$ cells $/ \mathrm{ml}$ & 988 & 66.8 \\
\hline$>=350$ cells $/ \mathrm{ml}$ & 492 & 33.2 \\
\hline \multicolumn{3}{|c|}{ Number of pills taken per day in the last one month (1596) } \\
\hline \begin{tabular}{|l|l} 
One pill \\
\end{tabular} & 511 & 32.0 \\
\hline Two pills & 637 & 39.9 \\
\hline Three pills & 369 & 23.1 \\
\hline$>=$ Four pills & 79 & 4.9 \\
\hline \multicolumn{3}{|c|}{ Missed dose in the last one month $(n=1631)$} \\
\hline No & 1460 & 89.5 \\
\hline Yes & 171 & 10.5 \\
\hline \multicolumn{3}{|c|}{ Registered side effect $(n=1505)$} \\
\hline Side effect present & 246 & 16.3 \\
\hline Side effect Absent & 1259 & 83.7 \\
\hline
\end{tabular}

Table 3: Medical history and adherence of the study participants, Oromia Regional State, Ethiopia, 2015.

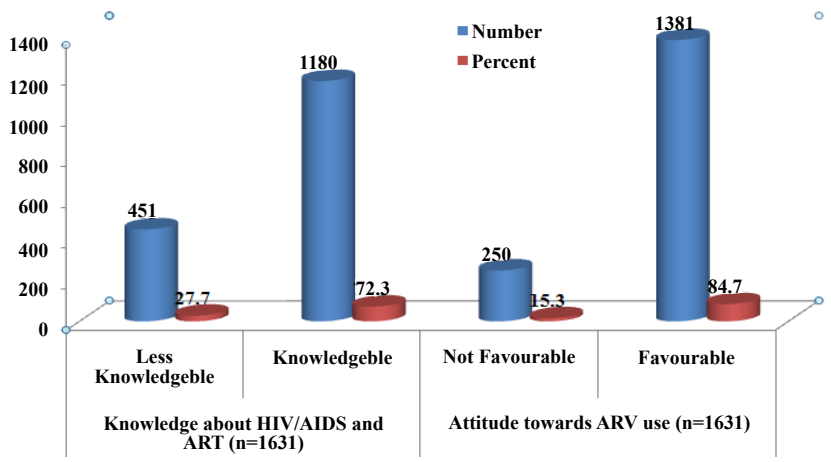

Figure 3: Knowledge and attitude of respondents towards HIVIAIDS and ARV, Oromia Regional State, Ethiopia, 2015.

1.92; 95\%CI: 1.06, 3.72). From the occupational status of respondents, housewives were more likely (COR: 4.77 ; 95\%CI: $1.25,18.29$ ) to adhere to ARV treatment compared to day laborers. Similarly, Married and cohabiting respondents were more likely to adhere to ART as compared to singletons.

In addition, no use of addictive substances was likely to increase adherence by odds of more than seven times (AOR: 7.42; 95\% CI: 1 . 46. 37.81). Those respondents who disclosed their ART status were (COR: 2.20; 95\% CI: 1. 10.4.41) more likely to adhere to ART than their counterparts. Baseline CD4 Count $<350$ cells/ml were two times more likely to adhere as compared to respondents with $\mathrm{CD}_{4}$ count $>350$ cell/ $\mathrm{mm}^{3}$.

However, no statistically significant relationships were observed between the sex of the respondents, religion, age, estimated monthly income, education, knowledge score, attitudes score, distance from a health facility, travel cost, social support, baseline functional status, WHO staging and other related variables. Stratified analysis using these factors also didn't show statistical significance with ART adherence.
Multivariate logistic regression was run to identify predictors of ART adherence and showed that being house wife (occupation) (AOR: 5.10; 95\% CI: 1.30, 19.98), Married (AOR: 2.19; 95\% CI: 1.13, 4.26), Baseline CD4 Count $<350$ cells/ml (AOR: 2.21 ; 95\% CI: 1.13, 4.34) and no use of addictive substances (AOR: 7.42; 95\% CI: 1.46, 37.81) were predictors of ART adherence.

\section{Discussion}

This study used both primary and secondary data. It showed that $97.2 \%$ of the patients took more than $95 \%$ of the prescribed doses correctly one month prior to the survey (good adherence status). This is in line with the study conducted by Tiyou et al. based on self report of missed doses of one-week recall before the actual interview indicating 95\% of the participants had good adherence (dose adherence) [13]. However, the level of adherence in this study is higher than the report from the Hospital based study from south and central Ethiopia in 2009 that indicted an adherence rate of $88.1 \%$, [7]. But, it is comparable with the studies done by Ayele et al. that showed adherence rate of $95 \%$ [13]. Another study done by Mekonnen et al. in the South West part of Ethiopia showed an overall adherence rate of $98.8 \%$ (98.1\% among males and $99.5 \%$ among females) [31]. A systematic review by Mills and colleagues showed a pooled adherence estimate of $77 \%$ ( $95 \%$ confidence interval, $68-85 \%$; based on a total of 12,116 patients) by sub-Saharan African patients [32]. One possible reason for these disparities could be that these studies used different methods to measure ART adherence; some used self report of missed doses from few weeks to months while others used pill count. The other reason for these variations could be attributed to the recent ART service decentralization to health centers which brings the service closer to the beneficiaries.

This study showed that housewives were found to be at increased likelihood of having good adherence to ART compared to the daily laborers. This could be due to the fact that daily laborers might be travelers and have no residential stability as compared to housewives.

Our study showed that no use of addictive substances was likely to increase adherence to ART. This result goes with the study done in Ethiopia that showed nonusers of addictive substances were more likely to adhere to ART than their counterparts. Drinking alcohol (AOR, $0.21 ; 95 \%$ CI: $0.07,0.62)$ was also associated with poor adherence in

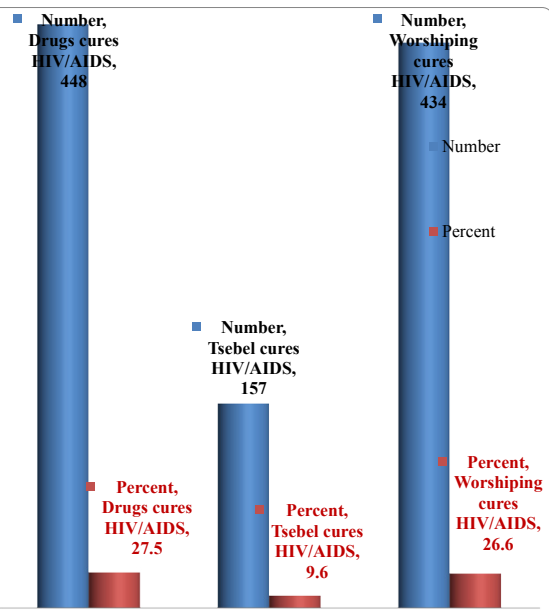

NB: Percentage may not add up to hundred as multiple answers were possible

Figure 4: Respondents believing HIVIAIDS is curable by worshiping and holy water, respectively. 
Citation: Chaka TE, Abeya SG, Adlo AM, Abebe TW, Hamuse SD, et al. (2016) Antiretroviral Therapy: Level of Adherence and Its Determinants Among Patients on Treatment in Different Health Facilities. A Cross Sectional Study in Oromia Regional State, Ethiopia. J AIDS Clin Res 7: 629. doi: 10.4172/2155-6113.1000629

Page 6 of 7

\begin{tabular}{|c|c|c|c|c|c|c|c|}
\hline \multirow{2}{*}{ Variables } & \multirow{2}{*}{ Category } & \multicolumn{2}{|c|}{ Adherence status } & \multirow[t]{2}{*}{ COR } & \multirow[t]{2}{*}{$95 \% \mathrm{Cl}$} & \multirow[t]{2}{*}{ AOR } & \multirow[t]{2}{*}{$95 \% \mathrm{Cl}$} \\
\hline & & Good No (\%) & Fair to poor No (\%) & & & & \\
\hline \multirow{2}{*}{ Residence } & Urban & $1310(82.6)$ & $32(71.1)$ & 1.00 & & 1.00 & \\
\hline & Rural & $276(17.4)$ & $13(28.9)$ & 1.92 & $1.06,3.72^{*}$ & 1.42 & $0.66,3.05$ \\
\hline \multirow{6}{*}{ Occupation } & Day laborer & $424(26.7)$ & $15(33.3)$ & 1.00 & & 1.00 & \\
\hline & Farmer & $138(8.7)$ & $8(17.8)$ & 2.91 & $0.84,10.16$ & 2.34 & $0.62,8.81$ \\
\hline & Housewife & $255(16.1)$ & $7(15.6)$ & 4.77 & $1.25,18.29^{*}$ & 5.10 & $1.30,19.98$ \\
\hline & Business owner & $339(21.4)$ & $7(15.6)$ & 2.26 & $0.58,8.84$ & 1.34 & $0.31,5.76$ \\
\hline & Employee & $247(15.6)$ & $3(6.7)$ & 1.70 & $0.44,6.64$ & 1.13 & $0.25,5.20$ \\
\hline & Others & $183(11.5)$ & $5(11.1)$ & 2.25 & $0.53,9.53$ & 1.47 & $0.24,9.17$ \\
\hline \multirow{5}{*}{ Marital Status } & Single & $227(14.3)$ & $1(2.2)$ & 1.00 & & 1.00 & \\
\hline & Married & $817(51.6)$ & $30(66.7)$ & 8.34 & $1.13,61.45^{\star}$ & 2.19 & $1.13,4.26^{*}$ \\
\hline & Divorced & $175(11.0)$ & $4(8.9)$ & 5.19 & $0.58,46.83$ & 6.02 & $0.64,56.60$ \\
\hline & Widowed & $231(14.6)$ & $7(15.6)$ & 6.88 & $0.84,56.36$ & 7.96 & $0.93,68.36$ \\
\hline & Others & $134(8.6)$ & $3(6.7)$ & 5.08 & $0.52,49.35$ & 5.90 & $0.58,59.86$ \\
\hline \multirow[t]{2}{*}{ Use Addictive substance } & Yes & $158(10.6)$ & $9(21.4)$ & 1.00 & & 1.00 & \\
\hline & No & $1328(89.4)$ & $33(78.6)$ & 2.29 & $1.10,4.88^{*}$ & 7.42 & $1.46,37.81^{*}$ \\
\hline \multirow{2}{*}{ Disclosure of ART status } & Yes & $1337(87.2)$ & $34(75.6)$ & 2.20 & $1.10,4.41^{*}$ & - & - \\
\hline & No & $202(12.8)$ & $11(24.4)$ & 1.00 & & 1.00 & \\
\hline \multirow{2}{*}{ Baseline CD4 Count } & $<350$ cells/ml & $971(67.2)$ & $17(48.6)$ & 2.17 & $1.11,4.21^{*}$ & 2.21 & $1.13,4.34^{*}$ \\
\hline & $>=350$ cells $/ \mathrm{ml}$ & $474(32.6)$ & $18(51.4)$ & 1.00 & & 1.00 & \\
\hline
\end{tabular}

Adjusted for the variables in the model

Table 4: Factors associated with adherence to ART among patients living with HIVIAIDS, Oromia Regional State, Ethiopia, 2015.

the study done by Simoni et al. [7]. This might be due to the fact that addictive substance users are prone to forget their medication schedules and have impaired social life. ART disclosure status was significantly associated with good adherence to ART in the current study.

This study also showed that patients with baseline $\mathrm{CD}_{4}$ count of less than 350 cells $/ \mathrm{ml}$ were more likely to adhere to ART. This may be attributed to the focus of attention given by patients for they already experienced the illnesses. Health care workers also may give less attention for those patients who look apparently healthy.

The knowledge level of respondents was not adequate (72.3\%), although it was not found to be statistically significant association with adherence. Similarly, the attitude of the respondents towards ARV drugs was favorable for $84 \%$ of them. This gap might have contributed for seeking other options than ART like worshiping (26.6\%) and holy water $(9.6 \%)$.

This study identified some patient characteristics (use of addictive substances, base line CD4 count more than $350 / \mathrm{mm}^{3}$ and being unmarried) that directly affects ART adherence. These set of patients need to be given special attention during adherence preparation.

\section{Conclusion}

The level of adherence to ART was very high (97.2\%). Married respondents and those who do not use the addictive substance adhere more to ART. $\mathrm{CD}_{4}$ count less than $350 \mathrm{cell} / \mathrm{mm}^{3}$ and those respondents who disclosed their ART status had optimum adherence to ART. Moreover, significant proportions of patients believe that use of worshiping and holy water can cure HIV/AIDS. Health education should be provided for ART clients to increase their knowledge and attitude towards HIV/AIDS. The study finding showed optimal ART adherence in the region and this achievement should be maintained. The pre ART adherence preparation should be given due attention for day laborers, addictive substance users and unemployed people by all stakeholders. Also, the knowledge and attitude of the patients towards the course of HIV/AIDS should be given due emphasis.

\section{Author's Contribution}

All the authors were responsible for the design and conduct of the study. Analysis, interpretation of findings and drafting of the manuscript were done by the authors. The authors have read and approved the final content of the manuscript.

\section{Acknowledgement}

We would like to thank RHB for financial support to conduct this study and for giving relevant enrichments of the research ideas. We also acknowledge AHMC for facilitating forthe research process. The study facilities, data collectors and supervisors are acknowledged for their unreserved cooperation without whom this study would not have been realized. Last but not least, we would like to extend our gratitude to our study participants.

\section{Funding}

This study was sponsored by ORHB

\section{References}

1. WHO (2006) Antiretroviral therapy for HIV infection in adults and adolescents Recommendations for a public health approach.

2. WHO (2002) The use of antiretroviral therapy: A simplified approach for resource constrained countries. WHO project: ICP HIV 001

3. Jane M, Amico KR, Smith L, Nelson K, et al. (2010) Antiretroviral adherence interventions: Translating research findings to the real world clinic. Curr HIVI AIDS Rep 7: 44-51.

4. Alagaw A, Wanzahun G, Mohammed T, Tariku D, et al. (2014) Factors associated with antiretroviral treatment adherence among adult patients in Wolaita Soddo Hospital, Wolaita Zone, Southern Ethiopia. Science Journal of Public Health. 2: 69-77.

5. Rutherford GW Anglemyer A, Easterbrook PJ, Horvath T, Vitoria M, et al. (2014) Predicting treatment failure in adults and children on antiretroviral therapy: A systematic review of the performance characteristics of the 2010 WHO immunologic and clinical criteria for Virologic failure. AIDS 28: S161-S169.

6. Gilks CF, Crowley S, Ekpini R, Gove S, Perriens J, et al. (2006) The WHO public-health approach to antiretroviral treatment against HIV in resourcelimited settings. Lancet 368: 505-510.

7. Simoni JM, Amico KR, Smith L, Nelson K (2010) Antiretroviral adherence interventions: Translating research findings to the real world clinic. Curr HIV/ AIDS Rep 7: 44-51. 
Citation: Chaka TE, Abeya SG, Adlo AM, Abebe TW, Hamuse SD, et al. (2016) Antiretroviral Therapy: Level of Adherence and Its Determinants Among Patients on Treatment in Different Health Facilities. A Cross Sectional Study in Oromia Regional State, Ethiopia. J AIDS Clin Res 7: 629. doi: $10.4172 / 2155-6113.1000629$

Page 7 of 7

8. Li L, Lee SJ, Wen Y, Lin C, Wan D, et al. (2010) Antiretroviral therapy adherence among patients living with HIVIAIDS in Thailand. Nurs Health Sci 12: 212-220.

9. Shumba C, Atuhaire L, Imakit R, Atukunda R, Memiah P (2013) Missed doses and missed appointments: Adherence to ART among adult patients in Uganda. ISRN AIDS 2013: 270914

10. Markos E, Worku A, Dave G (2008) Adherence to ART in PLWHA at Yirgalem Hospital, South Ethiopia. Ethiop J Health Dev 22: 174-179.

11. World Health Organization (2008) Determinants of adherence to antiretroviral treatment: An explorative study at health facilities in Ethiopia and Uganda. INRUD.

12. Mekonnen, Yared, Sanders R, Tibebu S, Emmart $P$ (2010) Equity and access to ART in Ethiopia. Futures Group, Health Policy Initiative, Task Order 1 , Washington, DC.

13. Tiyou A, Belachew T, Alemseged F, Biadgilign S (2010) Predictors of adherence to antiretroviral therapy among people living with HIVIAIDS in resource-limited setting of southwest Ethiopia. AIDS Res Ther 7: 39.

14. Ickovics JR, Meade CS (2002) Adherence to HAART among patients with HIV: Breakthroughs and barriers. AIDS Care 14: 309-318.

15. Bock P, James A, Alliance N, Peton N, Kalpana S, et.al (2016) Baseline CD4 count and adherence to antiretroviral therapy: A systemic review and metaanalysis. JAIDS Journal of Acquired Immune Deficiency Syndromes 414

16. Tadios $Y$, Davey $G$ (2006) Antiretroviral treatment adherence and its correlates in Addis Ababa, Ethiopia. Ethiop Med J 44: 237-244.

17. Gao X, Nau DP, Rosenbluth SA, Scott V, Woodward C (2000) The relationship of disease severity, health beliefs and medication adherence among HIV patients. AIDS Care 12: 387-398.

18. Bosworth HB (2005) Patient treatment adherence: Concepts, interventions and measurement. Mahwah: Lawrence Erlbaum Associates, Publishers.

19. Chesney MA (2000) Factors affecting adherence to antiretroviral therapy. Clinical Infectious Diseases 30: S171.

20. World Health Organization (2008) Determinants of adherence to antiretrovira treatment: An explorative study at health facilities in Ethiopia and Uganda. INRUD.

21. Melissa W, Maman S, Earp JA, Eng E, Setel P, et al. (2009) It's all the time in my mind': Facilitators of adherence to antiretroviral therapy in a tanzanian setting. Social Science \& Medicine 68: 1793-1800.

22. Maria R, Busza J, Wringe A, Mbata D, Urassa M, et al. (2009) Barriers to sustaining antiretroviral treatment in Kisesa, Tanzania: A follow-up study to understand attrition from the antiretroviral program. AIDS Patient Care and STDs 23: 203-210.

23. Beyene KA, Gedif T, Gebre-Mariam T, Engidawork E (2009) Highly active antiretroviral therapy adherence and its determinants in selected hospitals from south and central Ethiopia. Pharmacoepidemiology and Drug Saftey 18: 10071015.

24. Amberbir A, Woldemichael K, Getachew S, Girma B, Deribe K (2008) Predictors of adherence to antiretroviral therapy among HIV-infected persons: A prospective study in Southwest Ethiopia. BMC Public Health 8: 265

25. Debito T, Deyno S (2014) Rate and predictors of adherence to antiretrovira therapy among clients on antiretroviral therapy at Tepi Health Center, southwest Ethiopia. Sci Technol Arts Res J 3: 93-98

26. Reda AA, Biadgilign S (2012) Determinants of adherence to antiretrovira therapy among HIV-infected patients in Africa. AIDS Res Treat 2012: 574656.

27. Hailasillassie K, Etana B, Alemayehu M, Fisseha G (2014) Factors associated with adherence of highly active antiretroviral therapy among adult HIVIAIDS patients in Mekelle Hospital, Northern Ethiopia. Science Journal of Public Health 2: 367-372.

28. ORHB (2013/2014) Oromia regional health bureau report.

29. Alagaw A, Wanzahun G, Mohammed T, Tariku D, et al. (2013) Factors associated with antiretroviral treatment adherence among adult patients in Wolaita Soddo Hospital. Journal of Tropical Diseases 1: 4.

30. Asmare M, Aychiluhem M, Ayana M, Jara D (2014) Level of ART adherence and associated factors among HIV sero- positive adult on highly active antiretroviral therapy in Debre Markos Referral Hospital, Northwest Ethiopia. J Antivirals \& Antiretrovirals 6: 120-126.

31. Ejigu MA, Mohammed MA (2014) Anti-retroviral therapy adherence and its determinants among adult patients living with HIVIAIDS in South West Ethiopia: A facility-based cross sectional study. Gaziantep Med J 20: 52-58.

32. Mills EJ, Nachega JB, Buchan I, Orbinski J, Attaran A, et al. (2006) Adherence to antiretroviral therapy in sub-Saharan Africa and North America: A metaanalysis. Journal of the American Medical 296: 679-690. 